\title{
Ciencias de la comunicación $y$ sociedad: un diálogo para la era digital - Perspectivas mundiales
}

Resumo

As tecnologias digitais têm propiciado novas formas de socialização e a emergência de práticas culturais que acabam sendo também conceitual e teoricamente, objeto novo e primordial de estudos. O presente texto avança na análise do nexo decorrente dessas inovações no contexto entre sociedade e comunicação e das implicações daí derivadas.

\section{Estrategias globales para la sociedad digital.}

La transición a la era digital de la comunicación comporta un fenómeno que desborda el terreno de lo tecnológico. El hecho de que se hable de una Sociedad de la información implica una condición política (el rol de los estados y naciones ) y una condición social (todas las personas tienen derecho a las funciones $y$ propiedades de la información). El principio de la razón teórica de que esto es beneficioso para toda la sociedad es la clave para afrontar la transformación de las ciencias de la comunicación: la actitud crítica ante los nuevos desafíos científicos $y$ técnicos. El principio de la razón práctica nos pone ante una actitud constructiva para la formación de las nuevas generaciones de creadores $\mathrm{y}$ gestores de lo medios de comunicación. La razón teórico práctica servirá para recordamos que el éxito de los desafíos que tiene la nueva sociedad no pueden realizarse sin el conocimiento de los condicionamientos económicos y comerciales que regulan el intercambio comunicativo y que, por encima de todo, los valores éticos y universales de la justicia, igualdad y respeto a la dignidad humana constituyen el criterio referencial de todo investigador.

A la situación actual caracterizada por una extrema complejidad se ha llegado a través de una evolución marcada especialmente por el mayor progreso tecnológico de lo digital, la rápida y radical modificación del entorno económico y financiero mundial, la tendencia global a la dereglamentación y a la privatización en todos los sectores, pero principalmente sensibles en la comunicación, y la progresiva importancia adquirida por los bienes inmateriales entre los consumidores.

En el aspecto social, una nueva etapa se abre por delante se define por la migración a la sociedad de la información, pero también por una pérdida de la territorialidad de origen y por la emergencia de nuevas instancias de mediación en la cultura, la educación, los servicios y el consumo. Sabemos que el potencial de oportunidades es tremendamente desigual entre el Norte y el Sur de la riqueza y el desarrollo. A la euforia con que se recibe en el primer mundo las nuevas oportunidades del conocimiento y del bienestar se opone el pesimismo de quienes sospechan del peligro de creación de nuevas zonas de infoparias . Este escenario mundial crea razonadas incertidumbres sociales ante las manifestaciones de optimismo económico por parte de grandes empresarios e inversores como único criterio de valor. Pero también sabemos que el füturo de la sociedad digital depende en gran parte de las medidas de equilibrio entre usuarios, mercado de las redes y responsabilidad política. El equilibrio en el acceso a la Sociedad de la 
información es, en última instancia, un ejercicio de aplicación de los valores universales y la democracia.

El riesgo de un mundo más conectado pero más desigual puede venir tanto por el lado de una sociedad dominada por los mercaderes como por el abandono de las responsabilidades por parte de los individuos y de los agentes sociales.

Sabemos que la era digital comporta cambios estructurales. La materia y la forma de los medios de comunicación, los sistemas de circulación del conocimiento y los vínculos que tejen la red social han comenzado ya a ser transformados.

Sabemos que como en toda etapa histórica, nos encontramos en una era de transición o migración digital cuya duración nadie puede prever. Los científicos y profesionales de la comunicación están llamados a ser vigilantes ante la evolución de las repercusiones culturales y sociales de las telecomunicaciones, de las redes del conocimiento estructuradas en tomo a Internet y de la adaptación o transformación de los medios de comunicación tradicionales.

Los mercados y las tecnologías de las telecomunicaciones han comenzado ya a cruzar la frontera de los territorios y Estados; Internet ha acelerado aún más la tendencia al desequilibrio lingüístico entre el inglés y todas las demás lenguas; los medios de comunicación tradicionales se encuentran a la defensiva frente a las estrategias de fusiones y fisiones que los operadores internacionales, principalmente desde el capital norteamericano, han emprendido a partir de la liberalización impuesta en el mundo, mientras los Estados Unidos se reservan el proteccionismo para ellos.

El discurso de la independencia de los medios se toma cada vez menos verosímil, y tampoco será fácil seguir manteniendo la individualidad de soportes, géneros y formatos de la radio, prensa, televisión que ya están siendo integrados en vastas zonas multimedia . La integración de los medios significa también la incor- poración de nuevas lógicas del saber hacer de los profesionales, de las estrategias comerciales y de los contenidos. El desembarco de profesionales externos a la tradición periodística en la formación y la cultura de los medios, provenientes de la ingeniería, la informática, las artes visuales $y$ el marketing ya ha comenzado a tener sus efectos sobre el producto final. Del mismo modo en que los novelistas se hicieron cargo de las columnas culturales de la prensa del siglo pasado cuando los dueños de periódicos se enteraron de que de verdad, lo que interesa a los lectores es que les cuenten historias bien escritas (García Márquez dixit).

La era digital encuentra a la radio, prensa y televisión en un estado de conservación muy diferente del sus orígenes, habiendo sido sometidos a continuas migraciones de formatos, géneros y prácticas profesionales. Los públicos o destinatarios de los medios también se han acostumbrado a emigrar al ritmo de las nuevas ofertas de medios y programas.

Asi que cuando llegó Internet, el usuario integró casi naturalmente el computador junto al televisor y la prensa en el otro. Las progresivas oleadas de usuarios que Internet roba a la televisión son, desde 1998 poco significativas en Europa. Aunque lo suficiente para anunciar que el número de usuarios de la red aumenta en forma exponencial.

Pero hay sorpresas, y por tanto nuevas situaciones para analizar en profundidad tanto para los inversores como para los científicos sociales. Por un lado el recuperado prestigio del texto lingüístico que había perdido importancia a favor de una gran polución de imágenes. Y el resurgir de la magia del teléfono a la par que su transformación tecnológica o por causa de ella. Lo cierto es que hoy escribimos más que antes gracias al computador. Pero también, y esto es privilegio de los más jóvenes, en el teclado del teléfono móvil. ¿Quién había dicho que la escritura moría y que la comunicación oral perdía su fuerza 
social? Hoy escribimos y hablamos más a través de interfases que no cesan de evolucionar. Pero esa misma evolución podría llevar a la desaparición del teclado a favor de la conversión textual de la palabra sonora. Al mismo tiempo, comenzamos a vemos en una larga guerra librada en el terreno estratégico de la comunicación. ¿Quién tendrá mando en plaza en el futuro próximo: las telecomunicaciones, la información periodística o los medios audiovisuales? De aquí nacerá la próxima era de la comunicación que será dominada por una de estas tres tendencias del negocio mundial.

Mientras tanto, las ciencias de la comunicación se encuentran en un escenario disputado por un discurso polarizado entre dos sectores de pensamiento. El discurso pesimista según el cual hay una sola economía y un solo mercado globalizados lo que facilita la pandemia del Pensamiento Unico. El discurso moderadamente optimista según el cual las nuevas zonas abiertas por los nuevos modelos económicos regionales y por el protagonismo efectivo en el ejercicio de la democracia comunicativa son perfectamente legítimas y pueden proporcionar un nuevo impulso histórico para la toma de responsabilidades personales y la exigencia a los poderes públicos. Los activistas de la movilización antiglobalización de Davos a Porto Alegre, pasando por Barcelona y de retomo a Porto Alegre nos demuestran durante el breve camino recorrido hasta ahora que no basta la denuncia sin el ejercicio de la imaginación solidaria pero inteligente para la propuesta de soluciones. El alto valor concedido a la innovación y el entusiasmo por las oportunidades abiertas por Internet y las tecnologías de la comunicación no es patrimonio ni competencia exclusiva de Norteamérica. El proyecto Galileo para la creación de una constelación de 30 satélites de comunicación europeo, que comenzó a finales del siglo XX y que entrará en funcionamiento dentro de 6 años es un sistema global de navegación por satélite alternativo al GPS norteamericano y al GLONASS ruso que fueron concebidos en los años 70 con fines exclusivamente militares. El Galileo, que abrirá enormes posibilidades a las telecomunicaciones tiene objetivos civiles y servirá para mejorar las prestaciones a los usuarios en el transporte por carretera, la prospección de fúentes de energía y la seguridad y gestión del espacio aéreo. Pero es bastante probable que estará también al servicio de los objetivos de la vigilancia y la observación en tiempo real de toda la geografía espacial, marítima y terrestre. El sueño del Gran Hermano.

\section{Desafíos del estado del arte para la formación y el empleo en el ámbito de la comunicación}

La migración técnica y social que ha emergido en estos años se caracteriza principalmente por cinco rasgos que expondremos brevemente antes de proponer los principales puntos de discusión sobre los desafíos en el ámbito de lo profesional que en mi opinión tendrán que atender las ciencias de la comunicación.

La digitalización de las telecomunicaciones, de los contenidos de textos, imágenes y sonidos, los soportes y terminales de comunicación han acelerado la convergencia de todos los medios. Este universo digital se ha canalizado a través de Internet, la telefonía móvil y la televisión digital (en sus modalidades de satélite, cable o terrestre) y van a parar directamente a los públicos a través de la modalidad de consumo en forma de redes. En la primera etapa digital, los consumidores han comenzado a integrar espontáneamente los soportes digitales multimedia como el $\mathrm{CD}$ de datos y música y el DVD así como a conectarse a la red de Internet. Pero todavía estamos sin saber si ocurrirá una integración o una desagregación de terminales actualmente en fase de experimentación. Las modalidades de recepción social son por ahora inciertas respecto a su uso familiar, 
individual y profesional así como a los tipos de actitud sicológica frente a la interactividad, conectividad y movilidad de los contenidos en oferta.

Congregadas la revolución digital y la diversidad de expectativas de los consumidores nos encontramos ante una sola certidumbre: la de que los modelos clásicos de teorías y técnicas de la comunicación serán tan obsoletas como lo será el modelo clásico de difusión del conjunto de los medios, de la producción de los contenidos y de la oferta de servicios que dominaron el siglo XX.

Las ciencias de la comunicación se encuentran ante la necesidad de responder al desafio de que los actores del sector de las telecomunicaciones, del audiovisual y multimedia así como de la informática no esperarán la renovación de las universidades para orientarse frente a las nuevas empresas en la preparación de las nuevas profesiones y en la competencia necesaria para la gestión y la producción de nuevos contenidos

El informe de la Asociación Europea de Periodistas ${ }^{1}$ adelantándose a los departamentos universitarios de comunicación aportaron ya en 1998 algunas lineas de reflexión sobre la empresa multimedia del futuro y las nuevas formas de ejercicio de la profesión así como las necesidades de una formación adecuada a la nueva situación.

En términos generales, y más allá del informe de Maastrich, se pueden indicar algunas tendencias del desarrollo de la comunicación que incidirán directamente en el ámbito de la investigación y la formación en ciencias de la comunicación.

La migración hacia la informatización en el conjunto de la producción audiovisual supondrá un cambio en la preparación cultural de los profesionales. Los técnicos empleados en distintas fases de la cadena de producción multimedia deberán ser polivalentes. Tanto la organización empresarial como el ejercicio de la profesión tenderán a imponer la estructura del sistema informático. El uso de la documentación en línea y el énfasis en la posproducción convertirá a los profesionales de creadores únicos en mediadores del proceso.

La movilidad y la internacionalización del mercado del trabajo en el ámbito de la comunicación ya es un hecho y bastaría con ver las ofertas de trabajo en la red para ámbitos del desarrollo social en comunicación

La contaminación de la actividad técnica con la creación de contenidos multiplicará el número de interfases pero reducirá notablemente el número de personas. Los productores de contenidos serán técnicos y los técnicos deberán ejercer tareas de contenidos. Las empresas de comunicación se preparan para esta fusión de competencias profesionales. Las continuas fusiones empresariales en el ámbito de la comunicación no son diferentes de las prácticas en otros dominios de la economía. Como ejemplo, las corresponsalías de grandes conglomerados de televisión reducen el número de empleados porque sus dueños saben que una buena reestructuración puede cotizar tan bien en bolsa como una buena inversión económica ( y además siempre habrá estudiantes dispuestos a trabajar gratis en lo que eufemísticamente se llama "practicas" de empresa). En la prensa de los grandes periódicos un corresponsal trabaja para varias secciones, un free lance se puede ocupar de varios medios internacionales, un estudiante universitario, si es buen fotógrafo amateur, puede ganarse la vida ofreciendo sus reportajes a periódicos y revistas ahorrando engorrosos contratos de trabajo a la empresa.

El rápido desarrollo de la tecnología de reproducción digital de la imagen y del sonido exigen nuevas condiciones $\mathrm{y}$ prestaciones para los artistas $\mathrm{y}$ diseñadores en el campo de la televisión, video juego, y entornos en línea.

La emergencia de la producción digital conlleva la emigración de la industria de la difusión a la industria de la distribución de archivos textuales, sonoros y visuales. La oferta de con-
(01) 1998, The Future of the

Printed Press challenges in a digital world, European Joumalism Centre, Maastricht; http://www. ejc.n//hp/fpp/ contents.html. 
tenidos será cada vez más diversificada a pesar de lo que las apariencias muestren lo contrario en este momento. Para la gestión de tales archivos serán necesarias nuevas competencias de aplicación y racionalización tanto en el ámbito informático como en el de la documentación. La profesión del documentalista multimedia será una de las nuevas profesiones con mayor futuro en el ámbito de empresas e instituciones para la explotación de nuevos mercados y democratización del acceso al patrimonio audiovisual universal.

La semiótica de la imagen y la competencia semántica tendrá cada vez mayor implicación en la construcción de sistemas de bases de datos icónicos y textuales para colaborar en la estandarización de patrones de búsqueda y en la cientificidad de criterios de lectura y segmentación automáticos.

Las posibilidades de acceso y de distribución de la información en Internet traerán consecuencias sobre la estructura y organización de los ámbitos de comunicación. Se están creando nuevas tareas tales como el director editorial y comercial, los periodistas en línea, los desarrolladores de web para cursos y plataformas de investigación. Muchas de las funciones que antes se desarrollaban en empresas pasarán a convertirse en teletrabajo individual y en casa.

Más allá de las nuevas competencias en el oficio de la comunicación, estamos ante una profunda reorganización de modelos de temporalidad productiva, que se trasladan desde estructuras lineales a modelos reticulares. La creación de las redes de trabajo permite la incorporación simultánea de periodistas, diseñadores gráficos, documentalistas en la prensa. $\mathrm{O}$ de los guionistas, productores, escenógrafos y realizadores sobre un mismo programa de televisión.

Las tareas que ios poderes públicos están obligados a desarrollar si quieren contribuir al desarrollo de la formación de nuevos profesionales en el ámbito de la comunicación pasan por buscar fórmulas imaginativas para permitir la formación continuada, favorecer el acceso a la informática desde la escuela elemental proveyendo de personal cualificado para la implementación de programas y plataformas educativas en todos los niveles de la educación no reglada. La formación universitaria de los futuros profesionales de la comunicación podría estar definitivamente condicionada desde la educación básica.

Más allá de los ámbitos empresariales, profesionales y educativos, es todo el universo cultural y social que se encuentra en plena transformación y mienten quienes afirman que la globalización es una cuestión puramente económica (como afirma con razón Stigliz, premio nobel de Economía). Las nuevas redes tienen una propia dimensión cultural que trasciende la mera tecnología, los usuarios tienen su propia concepción sobre las dimensiones regionales en las que interactúan. Los conceptos y teorías que aplicamos al análisis de la nueva sociedad de la información deberán tener en cuenta cómo se verán afectados los procesos sociales por el cruce de dimensiones culturales heterogéneas. Por ejemplo, habrá que investigar cómo se conjugan las aproximaciones entre las ciencias humanas y la tecnología en los ámbitos regionales. ¿De qué modo las nuevas propiedades temporales de las tecnologías podrán gestionarse desde las culturas locales para introducir variables que reduzcan y abaraten el tiempo de la comunicación? ¿qué nuevas redes se han de crear, qué nuevos tratamientos de la información son necesarios para la restitución del legado cultural e identitario así como la creación de nuevas expresiones culturales? Latinoamérica tiene una original y rica historia de análisis críticos a los procesos de desarrollo así como importantes aportaciones a la comunicación y la educación popular que tienen en la Red un campo de posibilidades abierto ${ }^{2}$. 
Es evidente que la comunicación electrónica se ha hecho universal gracias a Internet. Pero los procesos sociales que se desarrollan en Internet son el resultado de acciones directamente relacionadas con los ámbitos geográficos, culturales y económicos. Algunas de ellas son:

a) La comunicación electrónica y su dependencia de los procesos de regionalización en el acceso, lengua, recursos técnicos, capacidad de gestión de grandes cantidades de información, etc.

b) Los efectos del cambio de la disponibilidad presencial por la disponibilidad en la red en el mundo laboral y empresarial.

c) Los efectos del distanciamiento espacio temporal en la educación, en la creación artística y cultural.

d) Los efectos del traslado a la red de los procesos comunicativos interpersonales. ¿Cómo afectarán a la convivencia entre diferentes niveles sociales y culturales los procesos de aprendizaje grupal de las comunidades creativas procedentes de diferentes regiones geográficas y lingüisticas? ¿En qué cambiará la comunicación interpersonal respecto de la temporalidad, la escritura, las comunidades y lenguas afines?

e) El análisis de las resistencias culturales a la integración de los ámbitos profesionales y sociales en las nuevas tecnologías.

f) El análisis de las resistencias al cambio en los procesos y modelos de gestión de lo público por parte de los representantes democráticos. Habrá que luchar contra una nueva indigencia, aquella de tipo cultural que sufren los dirigentes de lo económico y lo político.

g) El estudio de los flujos de integración de las redes de comunicación y los procesos de desintegración de los núcleos sociales tradicionales vertebrados en la familia, el barrio, la ciudad, la pertenencia nacional.

2. ¿Quien esta haciendo la nueva comunicación?
De los medios tradicionales a la batalla entre $\mathrm{I}+\mathrm{D}$ (Empresa e instituciones de Investigación y Desarrollo) e $\mathrm{I}+\mathrm{C}$ (invención y conocimiento de los sectores sin grandes recursos )

Estamos dispuestos a creer que la nueva sociedad de la comunicación la hacen cuatro señores que se llaman AOL Time Warner, Microsoft, Vivendi o Telefónicas?

El rol de la prensa y la televisión en el espacio público ha sido el centro del debate de la comunicación y la sociedad durante el siglo pasado.

La jibarización del análisis a favor de los tópicos y estereotipos que servían de excusa para la manipulación de la información por parte del poder (la objetividad de la información, el valor de la imagen por encima de la palabra, etc.) ha tenido todos los ingredientes de una larga confrontación entre agentes sociales, empresarios y teóricos de la comunicación que por ahora presenta un saldo favorable a la prensa por encima de los otros medios. Existen los amos de las empresas periodísticas, pero los profesionales tienen un amplio margen de responsabilidad en el producto informativo. Como resultado, se piensa no sin cierta razón, que si la prensa no hubiera sido inventada seguramente la democracia hubiera tenido más dificultades para universalizarse.

De la televisión, en cambio, muchos han llegado a dar por cierta la hipótesis de Williams según la cual, si ésta no hubiera sido creada igualmente nos habríamos inventado algo para divertimos estúpidamente. Para pasar posteriormente al convencimiento de que la televisión ha llevado hacia una perversión del espacio público, especialmente en lo concerniente a los valores de la política y la cultura. Pero quién puede negar que las imágenes catódicas nos han hecho menos ciegos sobre lo que pasa a nuestros vecinos y lejanos, aún cuando el derrumbe de un par de rascacielos o los tanques invasores destruyendo ciudades enteras sirvan para inocularnos la insensibilidad .
(02) Ver: Catálogo de sitios web para la investigación de la comunicación y el desarrollo; Univ. Católica Boliviana "San Pablo"La Paz, Mayo 2002 
Todo ello, ya sucedía antes de la aparición de Internet. Así que con el advenimiento de la Red se ha pasado espontáneamente a suscitar los mismos interrogantes en torno a las necesidades de incremento de los niveles democráticos de la sociedad a la que los medios tradicionales, radio incluida, no habrían sido capaces de dar respuesta .

Lo cierto es que, la prensa primero y luego la televisión se han originado en estrecha relación con las etapas de la democracia representativa del siglo pasado, periódicamente interrumpida por dictaduras de diverso calado en Latinoamérica, Europa y resto del mundo mundial.

Pero coincidiendo con Internet se abre una etapa de ejercicio de democracia participativa, tecnologías interactivas mediante y gracias a la conciencia de una mayor demanda de participación de los ciudadanos en la cosa pública y en las decisiones que les atañen como sujetos sociales.

Con el ingreso de Internet en el universo de la información, ocurre por primera vez en la historia de la comunicación una batalla que no ha hecho más que comenzar entre los grandes productores $\mathrm{y}$ distribuidores de contenidos y las iniciativas de los grupos de usuarios en todo el mundo en torno a las necesidades de la participación social y su proyección global más allá del ámbito geográfico local.

No se trata sólo de una distribución alternativa o competitiva con los grandes medios (las web contra los periódicos de referencia, ¿Le Monde Diplomatique i o la televisión de Alyasira frente a la Fox y las cadenas mundiales de la CNN después del 11 de setiembre del 2001. No se trata sólo de mensajes redistribuidos y comentados en forma alternativa, también se trata de tener capacidad para publicar en las grandes revistas científicas (500 dólares cuesta ser publicado en una revista científica norteamericana) ${ }^{3}$. Las iniciativas de las grandes empresas internacionales de la música contra la piratería de la manta (venta de CD musicales en las calles) y contra tecnologías de reproducción musical de bajo coste (un par de jóvenes españoles han inventado las freidoras de $\mathrm{CD}$ al precio de 1 Euro que pueden instalarse en las calles y que los tribunales han declarado legales) nos recuerdan que no son las tecnologías digitales las que crean los usos y la participación (la tendencia de empresas e instituciones de $\mathrm{I}+\mathrm{D}$ ), sino la capacidad de invención y conocimiento $(\mathrm{I}+\mathrm{C})$ de los usuarios que descubren las posibilidades de las tecnologías digitales.

Comunicación colectiva: Sociedades virtuales $x$ Comunidades virtuales

En la industria tradicional, la creación de riqueza en los medios de comunicación se da por medio de la captación de audiencias y las estrategias de fidelización del marketing. Pero el factor principal de riqueza de la nueva sociedad de la comunicación se basa en la simetría entre creación de conocimiento y su distribución en tiempo real. No se buscan audiencias sino visibilidad a través de la exposición en la red de información y recursos dotados de identidad social.

Hasta el momento hemos asistido a un dominio conceptual y efectivo de la comunicación de masas. ${ }^{4}$ Pero el término de comunicación colectiva tiene que ver con la interacción permitida por las tecnologías y la circulación horizontal de la información y las prácticas comunicativas.

La comunicación colectiva reconoce que todos los usuarios tienen derechos y capacidad para producir, archivar, usar y transferir información. $\mathrm{Y}$ tienen vocación de ser competitivos con los medios y empresas de la información.

Tienen una dimensión tecnológica preferente por las redes virtuales pero están reguladas por diferentes instancias (institucionales, profesional, artística, económica) y se rigen por el derecho, la moral, la democracia y la 
justicia..

Las sociedades virtuales se caracterizan por los usos sociales de la red. Se trata de una tendencia bastante extendida en Europa, pero ampliamente presente en las $\mathrm{ONG}$ internacionales, las universidades y las administraciones locales, asi como los grupos de intereses enucleados o amparados por alguna institución. Sus características principales:

- Aprovechar los recursos locales (cultura, economía, tecnología)

- Potenciar relaciones interpersonales y asociacionismo (local/ internacional)

- Crear servicios a la comunidad local e internacional

- Operar en el comercio sin ánimo de lucro, el trueque y transacción local

- Crear redes para el desarrollo de la educación e investigación

- Diseñar políticas de recursos territoriales (capital humano, capital del conocimiento)

- Inventar instancias de gobiernos locales ${ }^{5}$.

-Denunciar situaciones de injusticia, corrupción social, abuso de los derechos humanos.

Las comunidades virtuales son redes cerradas, autosuficientes (los cinéfilos, los que cultivan alguna manía). En cambio, las sociedades virtuales son abiertas y pueden ser redes como la Porto Alegre o la de portales educativos.

Hay que distinguir entre comunicación global y local, pero también entre comunidades y sociedades. Una sociedad es abierta, democrática, se rige por los principios de los derechos humanos y las reglas especificas de un sector social.

Una comunidad virtual de un Mud o juego de roles, tiende a ser jerárquica y no participa necesariamente del interés social.

Las comunidades virtuales, se autorregulan. Tienen una dimensión ética y subjetiva, se rigen por la interdependencia de intereses, afinidades $y$ no tienen objetivos políticos ni deseos de intervenir en la sociedad ni competir con los medios masivos. Pero además pretenden utilizar y crear tecnologías para fomentar sus propios intereses (propio de las academias) en el marco de la comunidad local y global.

En la comunicación colectiva (preferentes en los USA) pero en menor medida en Europa tienen las siguientes características: tienen por finalidad competir

- con los medios comerciales y públicos

- entre los medios de concentración y redes descentralizadas de información pública (diarios electrónicos como Vilaweb que hacen los propios lectores).

- entre la producción internacional de contenidos y producción nacional (formatos y contenidos,

- redes de entretenimiento, mezcladas con grandes portales (AOL)

- Son creativas, artísticas, culturales más que políticas

- Algunos de sus contenidos: información, cinefilia, intercambio y trueque de música, imágenes y programas, mercado de trabajo ${ }^{6}$.

Las comunidades virtuales no son patrimonio exclusivo de una democracia participativa desintitucionalizada, son también las formas de los nuevos mercados que las empresas tratan de constituir a medio plazo por medio de una imagen social bien implantada.

Las sociedades virtuales, por el contrario, no quieren estar fuera del sistema. Quieren intervenir, pero el acceso generalizado a una democratización de la participación en las redes no es impedido por las empresas capitalistas sino por las instituciones, los gobiernos locales o regionales que suelen llevar un considerable atraso en relación con la sociedad, tal como sucede en España respecto a Holanda o Alemania. Que en España la gran mayoría de los usuarios se conecten a Internet desde sus casas y no desde el trabajo o los centros educativos ha creado una gran desazón en Castells y otros observadores sociales. Las estructuras conservadoras de la educación y la institución cultural
(05) Infovila de Valencia http:// unw.infovila.net Cudad virtual dé́msterdam fundada en 1994 (06) Comunidad de adolescentes: http://umw.teen.com. Una comunidad gay: http:ll. latino.gay.com 
retrasan la migración efectiva de los ciudadanos. Muchas veces el problema del acceso democrático a la comunicación no está en la globalización sino en lo local. Se debería recordar a los poderes locales la obligación de definir una política transparente de accesos social sin trasladar a los grandes centros de poder mundial la responsabilidad final.

Los vicios de una "microglobalización" (comportamiento de las instituciones locales en función del poder político a corto plazo), el provincialismo y el nacionalismo auto excluyente pueden ser el obstáculo más importante para el desarrollo de una democracia participativa.

Se dice (Wolton): el mercado no puede ser el árbitro social de la comunicación, es necesario introducir la política en las estrategias de Internet. Y se dice también que la liberalización impone la economía por encima de la política cuando es la globalización la que precisamente hace política.

Las teorías de la comunicación tendrán que enfrentarse a estas nuevas estructuras de la comunicación. Por ejemplo, se están dando grandes cambios en las estrategias de agenda setting. Las sociedades virtuales permiten invertir las reglas de las agendas informativas de los medios tradicionales. Mientras que los medios periodísticos seleccionan a priori la información, los sitios web de las sociedades virtuales de algunos organismos acogen todo y son los usuarios los que con sus comentarios y reseñas seleccionan lo que debe permanecer. Así es como han saltado a los medios los casos de Mónica Lewinsky, las denuncias de abusos sexuales en la iglesia católica, el despliegue internacional del fenómeno zapatista, etc. Los movimientos contra la pena de muerte, contra la lapidación de las mujeres, etc.

Los cambios en las estrategias de recepción de los medios tradicionales a través de la historia de la comunicación moderna obligan a cuestionarr los tradicionales para- digmas defendidos en las teorías funcionalistas, la teoría crítica y los estudios culturales porque no incluyen a los miembros de las comunidades y sociedades virtuales. Habrá que repensar tanto las categorías individuales como sociales de la recepción en la comunicación.

3. ¿Donde se realiza la nueva comunicacion?

¿Cual es el nuevo espacio publico?

El desarrollo de las redes digitales de Internet y de la telefonía prosiguen la tendencia a la visibilidad y la transparencia dominante en la modernidad de los medios. Hay algunas paradojas, sin embargo: la informática nos permite la visión directa $\mathrm{y}$ mejorada de la realidad. Sin embargo, la producción numérica no se hace por transparencia sino por opacidad. Las imágenes y las mejoras de la visión se hacen a través de sistema de escritura alfanumérica. La base de la imagen sigue siendo la geometría.

Siempre se ha dicho que hay que proteger a las personas en su intimidad y los alcaldes tienen problemas para poner cámaras de vigilancia en las ciudades. Pero curiosamente la visión de la intimidad no ha venido desde fuera sino desde casa. El programa de televisión Gran Hermano es una forma de espectacularizar una tendencia cada vez más proclive a la autoepifanía. Las webcams son verdaderas micro estructuras de observación del espacio público/privado. La forma más difícil de controlar en el ciberspacio de la comunicación no es ni global ni local, sino microcomunitaria. La visibilidad digital y el acceso a la información del cuerpo y de la capsula doméstica es el gran desafío comunicativo del futuro que será posible a través de los teléfonos de cuarta generación. Se trata de una verdadera inversión de migración cuya geografía se expone desde dentro hacia fuera.

La saturación del yo por exceso de exposición a los medios de comunicación del último siglo ha saltado la 
barrera infranqueable entre lo privado y lo público. Si la televisión había impuesto un orden de visibilidad social (quien no sale en televisión no existe), ahora es el sujeto quien organiza el dispositivo de identidad. En esa experiencia de la web cam, lo importante no es la conciencia de ser mirado por la cámara, sino la percepción de su debilidad, de su dependencia de la situación de ser mirado para existir, de encontrarse en una espacio privado pero sin ocultarse ante un espacio público que vive de lo privado.

En una sociedad en la cual el ciudadano se halla sometido cada vez más al régimen económico de la privatización y la masificación de los individuos, el déficit de identidad se alimenta del narcisismo como sistema de sobrevivencia de las masas anónimas. Para ello, nada mejor que exponerse en tiempo real a la intimidad de los otros. Ciertamente también hay otras formas más espectaculares $\mathrm{y}$ sangrientas de afirmación del yo como los escolares que ametrallan de vez en cuando en Estados Unidos o en Alemania a sus profesores y compañeros, o algún desalmado que encañona y mata a un grupo de regidores en Francia. Pero ya sabemos que la responsable es la violencia en televisión!

\section{¿A qué distancia estamos de Enzerberger?}

La nueva consistencia del espacio público exclusivamente basado sobre el mito de la transparencia ya se había iniciado en los medios tradicionales pero tenía una estructura asimétrica. Más aumentaba el poder económico de las empresas mayor, era la concentración y la centralización de las decisiones relacionadas con la difusión y la creación de contenidos y programas. Hoy es posible un espacio público simétrico de comunicación. A mayor concentración de las empresas, cuanto más grandes son las fusiones y la concentración de poder (AOL Time Warner, Microsoft, Bertelman, etc) mayores son las oportunidades para la creación de redes de consumo y de acceso horizontal a los softwares: las web de intercambio gratuito de la música, del cine (La última versión de La Guerra de las Galaxias de Lukas ya había sido instalada en miles de ordenadores de adolescentes, los programas de Windows pueden copiarse al mismo tiempo que salen de las factorías. Aumenta el poder económico y político de los agentes capitalistas de la comunicación, pero aumentan también las posibilidades de gestión democrática del acceso, distribución y creación de contenidos.

Lo importante es que esto no ocurre al margen, sino precisamente gracias a la existencia de estas industrias pertenecientes a la gran red. Los movimientos antiglobalización se sirven de los mismos medios y lenguajes para llegar a los grandes espacios de opinión en el mundo. La alternativa de los medios está en los propios nuevos medios (véanse las web creadas en tomo a Seatle, Porto Alegre, Barcelona, etc).

Sin embargo esta simetría no significa que la transparencia y visibilidad haga parte de los grandes agentes del poder mundial. Bancos, gobiernos, moralidad pública de los administradores y de los partidos políticos están con frecuencia bajo el prisma de acusaciones por operaciones ilegales, paraísos fiscales, abusos de autoridad, corrupción . Pero en su conjunto, la sociedad tiene mayor acceso a la visibilidad de esa gestión y a los escándalos como el del Perú de Fujimori, de Enron en Estados Unidos, o del BBVA en España, pueden conocerse en detalle y bien documentados en todo el mundo conectado. ${ }^{7}$

\section{La mediacion tecnolgica}

El arte de la transparencia y el arte de la inmediatez no son simétricos

¿ Pero los nuevos medios, son tan rápidos como la realidad? El caso de las vertiginosas sucesiones presidenciales en Argentina primero y luego el fallido golpe de Estado contra Chavez nos han demostrado que los medios audiovisuales y la red de Internet son superados por los acontecimientos.
Véase la web del Banco mundial: unw. wordlbank org/ anticomuption, Verla web del
parlamento europeo:
n...mmw. europarleu, int/experts/ anticomuption, Verla web del
parlamento europeo:
.. mum. europarleu. int/experts/ defaultrintm 
¿Se pueden seguir definiendo los nuevos medios por su inmediatez?

Sea la televisión que los nuevos medios digitales reivindican la inmediatez y su capacidad de integrar o fagocitar a los otros. La televisión se presenta bajo el signo del directo y lo simultáneo (Gran Hermano, Operación triunfo). El cine recrea cada vez con mayor realismo lo inmediato para la percepción del espectador. La web camp pretende ponemos delante de la visión en permanencia de la cotidianidad mostrada. Las instalaciones artísticas nos presentan objetos, materiales y personas en su estado "natural".

Desde el Renacimiento en adelante, el arte y la arquitectura nos proponen la inmediatez (contra la mediación) y la transparencia (contra la opacidad).

Pero los nuevos medios se encuentran sumidos en una paradoja: y es que en la misma proposición de su objeto reside su desaparición. La realidad virtual, el último dispositivo de inmediatez inventado, propone la desaparición de toda mediación para dejar paso a la realidad. Los computadores son productos humanos, pero una vez que los programnas han sido escritos, los humanos están de más en este mundo. En el momento que el programador escribe un programa se está borrando a sí mismo.

Los interfases de la transparencia como el ratón (maus) y el escritorio que niegan la mediatez de los caracteres son como la perspectiva de Durero que eliminaba el caos a través de la construcción de un único punto de vista.

Las superficies de los periódicos se parecen hoy más a las paginas de las pantallas de portales y webs mientras que las noticias en televisión son cada vez más la expresión de la influencia del interfase grafico por encima de la imagen real.

En todos estos ejemplos hay una tensión entre espacio visual y realidad tan mediado y tan real que trasciende la mediación misma. La gente termina por preguntarse, ¿es real la realidad?

Diferencia entre la tecnología de los artistas y la tecnología de los ingenieros.
Durante los años 60 y 70 hubo una feroz batalla librada en el terreno del cine sobre el concepto de impresión de realidad como expresión de la ideología burguesa que se saldó con el alumbramiento de artistas deconstructores como J. L. Godard. Se trataba de suprimir todo aquello que fuera imitación de lo real, para encontrarse directamente con el proceso de construcción de lo real. Por ejemplo, si había una huelga de trabajadores, el film debería expresar esos momentos de huelga, por ejemplo, boicoteando imágenes y sonidos durante las secuencias rodadas durante la huelga.

Los ingenieros de la era digital por su parte tratan de que la tecnología no se vea o no se sienta. En cambio, los artistas de la modernidad trabajan con los materiales en modo que se puedan ver sus estructura (Tapies, Barceló). No es una ironía si digo que la telenovela Latinoamérica es un típico producto posmoderno: sus creadores consiguen que se note el paso del tiempo, adecuar el tiempo del discurso en la pantalla al consumo de tiempo sentimental del espectador. No es la historia, el argumento, la mimesis lo que importa verdaderamente, sino el proceso de desarrollo del melodrama. El tiempo es el evento principal del medio.

La saturación social de los medios que nos ha tocado vivir en el siglo pasado tiene que ver con el exceso de medios, de ruidos, de imágenes, que nosotros hemos confundido siempre con lo real de las cosas. La saturación es opacidad por exceso de inmediatez. La transparencia se consigue con la ausencia del medio.

\section{Mediacion de la experiencia}

Las aplicaciones de los hipermedios son actos explícitos de traslado o emigración de los medios tradicionales de la transparencia hacia el espacio digital. Los hipermedios y están dirigidos por los mismos objetivos: superar los límites de la representación y alcanzar lo real. ¿Qué es lo real? Las experiencias de 
los espectadores o usuarios desde el aspecto de actividad ejercida por medio de los interfases, asi como los aspectos de la recepción emocional. Es decir, la experiencia de participación en un evento ha desplazado la televisión de contenidos.

Los medios transparentes simulaban o trataban de borrar las trazas de la mediación. Los medios digitales buscan la saturación de la experiencia a través de la experiencia directa de la realidad.

Ejemplos: la música y el espectáculo de los MTV: no es el producto en si, sino el proceso de asistir a un evento globalizado (muchos canales diferentes de MTV en diferentes lenguas y estilos). O triunfo representa lo mismo. No es el producto (las canciones son todas remakes, mejor sus originales que sus imitadores). Pero es la experiencia del acontecimiento compartido lo que provoca emociones en los jóvenes. Los hipermedios no prometen la realidad sino la autenticidad de la experiencia compartida.

La migración digital señala el fin de los medios en su contexto para pasar a ser el contexto mismo. Por eso, hay que revisar la teorías de la comunicación, los paradigmas, las funciones y estructuras y la semiótica que ha tratado de apartamos del tiempo real convenciéndonos que la realidad no es más que un atado de signos.

El lenguaje que es mirado como un mediador visible entre los sujetos y la naturaleza, no es el único mediador. El fenómeno de la tecnociencia contemporánea consiste en una intersección migratoria entre el sujeto humano, el lenguaje y el mundo externo de las cosas. Esa intersección migratoria es la forma constituyente de la experiencia digital. Cada nuevo medio es una migración parcial o total desde otro medio y esto sólo se puede llevar a cabo con el concurso de sujeto, lenguaje y acción tecnológica.

Las teorias de la comunicación deben servir para comprender las practicas comunicativas de la industria y la sociedad que son inseparables de la migración digital. Para comprender que hay una revolución digital y que las culturas llevan sus propias formas de comprender su relación con los otros, la tradición, la religión, las lenguas, etc. hacia la Red. Las reglas con que se gobernaba la industria de la comunicación han cambiado en la última década del siglo XX tanto como las formas de gobernar de los poderes públicos $\mathrm{y}$ privados.

\section{La Tecnocomunicacion}

La tecnocomunicación se ha ido poniendo de moda en los años 90, fundamentalmente con la explosión de las teletecnologías y la universalización de la informática.

En el campo de las ciencias de la comunicación encontramos por una parte una tendencia antitecnología que prefiere continuar los estudios de la comunicación con conceptos y medios clásicos. Por otro, el uso abusivo, por superficial y acrítico, del vocabulario de la tecnologías , especialmente de la información. Y en tercer lugar, el peso excesivo de la mega comunicación internacional que desde los años 70 ha relacionado las tecnologías con el capitalismo y la dominación norteamericana especialmente en los ámbitos de la industria militar (que llevará equivocadamente a la atribución exclusiva de los orígenes militares de Internet).

$\mathrm{Y} \quad$ finalmente la negación la complejidad de los procesos técnicos por parte del posmodernismo nacido en las sociedades opulentas para situarse en una crítica nihilista y cínica a la comunicación .

Es así como la cuestión de las tecnologías queda fuera de la complejidad cultural (la devoción a la ingeniería de la comunicación en los años 80 , por ejemplo, con la llegada de los satélites de televisión) o bien, en las antípodas de la acepción que la disuelve en la cultura, como hace el posmodernismo.

Una de las explicaciones del abuso de la nomenclatura de la tecnología reside en el desplazamiento de la economía industrial a la economía de la comunicación, y en consecuencia al desarrollo de la empresas de comunicación que exigen cada vez más investigación para el desarrollo (I+D) - 
especialmente en los EE:UU, y en menor medida en Japón y Europa - y la búsqueda de la racionalización y la eficacia en la empresa con la implementación de la informática y de los interfases técnicos.

Esta última, la informática apare-ce como preponderante en el proceso de la gestión de la comunicación. De ahí que su papel se ve como independiente en relación a los contextos culturales, sociales simbólicos, así como ajena a la subjetividad e intersubjetividad humana.

Por otro lado, el exceso, abuso y frivolidad en la crítica de la deconstrucción de los textos culturales y la constatación de que la realidad de la que habla la información y la televisión es una realidad construida llevan a un alejamiento del papel objetivo que puede jugar la técnica en la sociedad (se desprecia la información técnica sin haberla estudiado ni practicado). Las leyes de la realidad son construcciones sociales. Mientras una parte importante de los recursos humanos de la investigación cultural de la comunicación se dedicaba a estudiar los términos de verdad, realidad, objetividad, convirtiéndolos en identificaciones simbólicas por obra y gracia del predominio del lenguaje en el constructivismo como ideología del posmodernismo.

Pero otra parte de recursos humanos en Estados Unidos se dedicaba a inventar la tecnología y a ganar mucho dinero de paso. La tecnología precisamente, que acentúa su espacio extra-cultural mientras se desarrolla sin cesar en las universidades norteamericanas apoyadas por los caza-oportunidades financieras en Silycon Valley.

La concepción extra cultural de las tecnologías de la comunicación, sustentadas por las fuertes inversiones privadas y públicas comienzan a ir a la par con la idea de autonomía de la técnica. En la técnica no hay moralidad pertinente, los individuos trabajan en la innovación, y esta es posible sólo si es tecnológica. Y mientras tanto los teóricos de la comunicación, fieles a su status de científicos, no tienen ningún poder de decisión sobre la orientación del desarrollo tecnológico. En la empresa se prefiere escuchar a un gerente comercial o a un informático, mientras que en los ámbitos políticos las ciencias de la comunicación han quedado reducidas a los gabinetes de comunicación .

Sin embargo, en la última década ocurre simultáneamente a la vindicación de la autonomía técnica un resurgimiento de la teoría crítica (Thompson, Giddens, Jameson). Se ponen en evidencia la complejidad, las interacciones diversas entre los individuos y los colectivos frente a las nuevas máquinas de la comunicación, así como a sus aspectos simbólicos. El valor que tienen estos estudios estriba precisa-mente en negar la autonomía a los procesos tecnológicos. La introducción de la descripción narrativa de los contextos del desarrollo capitalista de las tecnologías demuestra que la intersubjetividad tiene un rol importante. Entre los investigadores y productores de la comunicación (productores y periodistas) existe una estrecha relación de interdependencia basado en el concepto de las construcciones sociales. Los hechos son construcciones sociales, los conceptos de verdad y objetividad (de la información, por ejemplo) son el producto y no la materia prima de investigadores y periodistas.

Mientras tanto, la presión de la Sociedad de la Información contribuye a tomar en serio los procesos de racionalización y desarrollo que comportan las tecnologías de la comunicación. Se trata de procesos que se negocian en los ámbitos de las políticas industriales y tecnológicas de los gobiernos, en los cuales los economistas y los ingenieros tienen una autoridad preponderante. Estos procesos no están exentos de maniobras, manipulaciones y de presiones de grupos de interés políticos y empresariales. Por ejemplo, la postergación indefinida de la infraestructura del cable en España decidida en los años '80 para apostar por las plataformas satelitales que ahora están en crisis en toda Europa. O el retraso indefinido de la televisión digital en abierto que demuestra que los poderes públicos están más interesados en manejar a distancia el bocado de las nuevas empresas que en el desarrollo tecnológico. $\mathrm{O}$ el expansionismo de 
Telefónica o Vodafone por el mundo que se salda con pérdidas de miles de puestos de trabajo mientras se atasca el desarrollo de la banda ancha por fälta de cobertura en el territorio nacional.

Por su parte, la construcción de Europa ha servido para plantear una concepción más exigente de la construcción social y política de las tecnologías de la comunicación para subordinarlas a un proyecto de sociedad. Esto ha cristalizado en la Unión Europea en lo que se denomina el Programa Marco de $\mathrm{I}+\mathrm{D}$, que confirma el principio de la investigación en las comunicaciones como una investigación científica que ha de ser el motor de la transformación y el progreso social.

Frente al panorama anterior, las tendencias en la investigación de la comunicación contemporánea se puede representar a través de algunos rasgos característicos.

Por una parte, el desarrollo de una ciencia de la comunicación pasiva y no intervencionista (el estudio conductista de los efectos) que se enfrenta con técnicas y metodologías activas, operativas, productoras de conocimiento en el contexto real de la sociedad (las ciencias cognitivas aplicadas).

El desarrollo de un saber especulativo (epistemología de la comunicación ) que ha tenido pocas oportunidades para desarrollarse en las teorías de la comunicación, una semiótica que hay explotar en su vertiente empírica en el contexto tecnológico de la imagen y la gestión informática de la información documental. En cambio, otras disciplinas menos científicas, pero donde el cambio, la evolución y el saber instrumental son determinantes (como en el caso de la publicidad y los estudios de sicología y sociología aplicada a los análisis sobre los públicos) ha evolucionado rápidamente dentro del ámbito empresarial. ${ }^{8}$

La sociedad de la información y el futuro de las ciencias de la comunicación deberían estar estrechamente relacionadas para no perder definitivamente la apuesta por una sociedad basada en valores que no se limiten a invertir y ganar en bolsa como máxima aspiración en el mundo de la comunicación.
Las tecnologías de la comunicación y las tradiciones culturales de las diferentes regiones del mundo puede abordar con cierto éxito una relación entre la producción y la creación simbólica y física, técnica y crítica. La globalización no está predeterminada y tenemos todo el tiempo por delante para la ilusión utópica a pesar de la contingencia y precariedad con que en ciertas regiones del mundo los investigadores están obligados a desenvolverse. No es sólo una cuestión de responsabilidad social, es una condición de libertad y de creatividad frente a un füturo que, a pesar de todo, resta ampliamente abierto.

Las tecnologías digitales nos están desvelando progresivamente las articulaciones y las dinámicas posibles que pueden desarrollarse como formas de solidariedad a partir de la exploración de las redes y las comunidades o sociedades basadas en la interactividad.

Las ciencias de la comunicación no pueden escapar a las manifestaciones de solidariedad y la cultivación de la diversidad en las cuales se hallan inmersos muchos científicos y técnicos en el mundo. La reivindicación de la identidad pasa hoy por la defensa de la biodiversidad, la logodiversidad y la tecnodiversidad (cf. Gilbert Hottois, Conferencia de Nantes 2002). La sabiduría en las ciencias de la comunicación es también política. Es necesaria una doble aculturación. Por un lado, una formación y una cultura en las tecnologías de la comunicación globales y locales. Por otro una formación metacultural, una cultura multicultural que garantiza la diversidad simbólica de los referentes geográficos, artísticos y lingüísticos. Esta formación, que podríamos también llamarla multicomunicación por sus rasgos de tolerancia y diversidad, podría ser un buen punto de partida para que quienes nos dedicamos a las ciencias de la comunicación no perdamos de vista los logros de la civilización en medio del caos de la planetarización de los mercados, intereses y poderes en conflicto que forman una base sustancial de la Red.

(08) Como ejemplos de una
concepaión tradicional de la
comunicadón con efectos en la
distinción neta entre prádica y
teoría puede leerse en Hermes,
la revista del Centre National de
la Recherce Social, frentea
revistas como Reseaux de
Telecom Francia que presentan
un ensamblaje variado de
prádticas, técnicas y teorías.

